\section{MASCULINIDADE(S) NO BALÉ: GÊNERO E SEXUALIDADE NA INFÂNCIA}

\author{
MASCULINITY/IES IN BALLET: GENDER AND SEXUALITY IN CHILDHOOD
}

MASCULINIDAD(ES) EN EL BALLET: GÉNERO Y SEXUALIDAD EN LA INFANCIA

lleana Wenetz ${ }^{\star}$, Christiane Garcia Macedo**
Palavras chave:

Masculinidade.

Dança.

Identidade

de gênero.

Sexualidade.

Keywords:

Masculinity.

Dancing.

Gender identity.

Sexuality.

Palabras clave: Masculinidad.

Danza.

Identidad de género. Sexualidad.
Resumo: Fundamentado nos Estudos Feministas, Culturais e de Gênero, este texto analisa a relação de meninos e dança, a partir do caso do Rodrigo, praticante de balé e hip-hop, especialmente as condições de possibilidade que constituíram a prática dele. Foram realizadas observações etnográficas e entrevistas. Após a discussão sobre gênero e sexualidade na infância, analisou-se 0 caso de Rodrigo e discutiu-se a questão da dança e masculinidades, destacando que a experiência se deu desde o ensino infantil e com apoio da família, o que ilustra linhas de fugas possíveis na norma heteronormativa. Finaliza este trabalho uma reflexão sobre as condições de possibilidade às quais Rodrigo teve acesso para a prática do balé, apontando como elas possibilitam pensar sobre a relação práticas corporais e gênero/sexualidade.

Abstract: This text analyzes boys' relationship with dance based on Feminist, Cultural and Gender Studies, focused on the case of ballet and hip-hop dancer Rodrigo and the possibilities that supported the emergence of his practice. A series of Ethnographic observations and interviews were conducted. After the discussion on gender and sexuality in childhood, we analyzed Rodrigo's case and examined the issue of dance and masculinities, stressing that the experience took place during childhood education along with his family's support, pointing out possible escape lines from the heteronormative standard. The work ends by reflecting on the opportunities that provided Rodrigo with access to ballet and how they help looking into the link between bodily practices and gender/sexuality.

Resumen: Fundamentado en los Estudios Feministas, Culturales y de Género, este texto analisa la relación entre niños y danza, a partir del caso de Rodrigo, practicante de ballet y hip-hop, especialmente las condiciones de posiblidad que constituyeron su práctica. Se realizaron observaciones etnográficas y entrevistas. Después de la discusión sobre género y sexualidad en la infancia, se analizó el caso de Rodrigo y se discutió la cuestión de la danza y masculinidades, destacando que la experiencia se dio desde el jardin infantil y con apoyo de la familia, lo que ilustra líneas de fuga posibles en la norma heteronormativa. Finaliza este trabajo con una reflexión sobre las condiciones de posiblidad a las cuales Rodrigo tuvo acceso para la práctica del ballet, mostrando que éstas posiblitan pensar sobre la relación de prácticas corporales y género/sexualidad.
*Universidade Federal do Espirito Santo. Vitória, ES, Brasil. E-mail: ilewenetz@gmail.com

**Universidade Federal do Vale do São Francisco. Petrolina, PE, Brasil. E-mail: chrisgmacedo@gmail.com

Recebido em: 22-02-2019 Aprovado em: 14-08-2019 Publicado em: 09-12-2019

DOI https://doi.org/10.22456/1982-8918.90474 (c) (1) (9) Licence 


\section{ALGUMAS PALAVRAS...}

Este artigo deriva de dados de uma pesquisa maior, intitulada "Presentes na escola e ausentes na rua: brincadeiras de crianças marcadas pelo gênero e pela sexualidade", ${ }^{1}$ na qual se procurou problematizar as relações que podem ser estabelecidas entre gênero e sexualidade em crianças e os diversos espaços de vivências/construções das brincadeiras. Com essa finalidade e a partir dos Estudos Feministas, Culturais e de Gênero que se aproximam do viés teórico do Foucault, realizamos uma etnografia de um ano em uma escola pública de Porto Alegre/RS.

Partindo dessa observação, percebemos como o gênero atravessa/institui ou conforma as ações e os discursos de grupos de crianças, incluindo na pesquisa outros espaços do bairro, como o clube onde as crianças desenvolviam suas atividades. Neste texto, optamos por apresentar um recorte com o objetivo de analisar a relação de meninos e dança, a partir do caso do Rodrigo, ${ }^{2}$ praticante de balé e hip-hop, especialmente identificando as condições de possibilidade que constituíram sua prática. Esse caso se destacou porque ele era um dos alunos que mais realizavam atividade física dentro e fora da escola, o que já se constituía, naquele momento, em um dado original, pois a maioria das crianças observadas desempenhavam poucas praticas corporais. Mas também nos chamou a atenção porque, dentre essas, estava o balé.

0 artigo está organizado em quatro partes. Na primeira localizamos a discussão sobre gênero e sexualidade na infância. Depois apresentamos com mais detalhes o caso de Rodrigo, descrevendo também a metodologia utilizada e, em seguida, discutimos a questão da dança e masculinidade. Finalizamos com a reflexão sobre o que este caso pode nos ajudar a pensar sobre a relação atividades e gênero/sexualidade.

\section{GÊNERO E SEXUALIDADE NA INFÂNCIA}

O gênero é entendido aqui como um conceito que remete a todas as formas de construções sociais, culturais e linguísticas implicadas nos processos que operam na diferenciação de homens e de mulheres. Nesses processos, estão incluídos seus corpos dotados de sexo, sexualidade e gênero (MEYER, 2003). Autoras como Nicholson (2000), Scott (1995), Louro (1999) e Meyer (2003) destacam que as masculinidades e as feminilidades (re)construídas pelas crianças dependem também dos modos como suas vivências nos diferentes espaços são atravessadas e simultaneamente (re)constituídas no cotidiano e nos efeitos provocados por elas.

Meninos e meninas aprendem a ser de determinados modos. Essas aprendizagens se dão, sobretudo, por meio do corpo e das práticas corporais, esportivas e/ou lúdicas das crianças, produzindo, assim, corpos marcados pelo gênero e pela sexualidade. Contudo, cabe destacar que assumir essa noção de corpo não implica a negação de sua materialidade biológica, mas a mudança de olhar para as relações de poder-saber que constituem e nomeiam determinadas características corporais, visto que essas características seriam entendidas como diferenças fixas e essenciais, o que poderia legitimar a valorização de algumas práticas apenas como masculinas ou femininas.

Dita associação, tradicionalmente, relaciona a agressividade, a virilidade, a força e a coragem com a masculinidade; e a delicadeza, intuição, sensibilidade e medo com a feminilidade (JAKUBOWSKA; BYCZKOWSKA-OWCZAREK, 2018). Assim, crianças que não

1 A pesquisa foi aprovada no Comitê Ética com o número do protocolo 2008022, aprovado em maio de 2009. 2 Nome fictício. 
se encaixam nessas tradicionais expectativas tensionam nossa compreensão do que seria masculino ou feminino.

Nesse mesmo raciocínio, observamos a sexualidade das crianças, que é entendida como os diferentes modos de expressar desejos e prazeres, os quais têm uma dimensão social, já que as maneiras que os sujeitos utilizam para se expressar são tanto aprendidas socialmente quanto codificadas em um contexto em particular. Weeks (1999, p. 43) destaca que a sexualidade constitui uma "[...] série de crenças, comportamentos, relações e identidades construídas e historicamente modeladas". Além de ser uma questão pessoal, é social e politicamente "[...] construída, ao longo de toda a vida, de muitos modos, por todos os sujeitos" (LOURO, 1999, p. 11). Nesse sentido, ao compreender que a sexualidade é aprendida em um momento histórico específico, podemos entender como a sexualidade opera também, ainda conforme o autor, como um "dispositivo histórico" (1999, p. 11)3. Desse modo, a sexualidade tem "[...] tanto a ver com nossas crenças, ideologias e imaginações quanto com nosso corpo físico" (LOURO, 1999, p. 38), pois os diversos significados que atribuímos à nossa sexualidade e também ao nosso corpo são "socialmente organizados" e, ainda, amparados por uma "[...] variedade de linguagens que buscam nos dizer o que o sexo é, o que ele deve ser e o que ele pode ser" (LOURO,1999, p. 43).

Na lógica heteronormativa, compreendemos que, ao termos um corpo de menino/menina, teríamos um comportamento de gênero (masculino/feminino) e uma sexualidade adequada (heterossexualidade). Dita linearidade é tensionada quando alguns desses elementos da tríade fogem a ela. Mas tanto a identidade de gênero quanto a sexual são processos contínuos e não homogêneos. Assim, quando uma menina joga futebol ou anda de skate ou um menino dança balé, a identidade deles é questionada, dizendo sobre a masculinização das meninas ou da homossexualidade dos meninos.

\section{CLUBE, A DANÇA E O MENINO}

A pesquisa teve como cenário a cidade de Porto Alegre/RS, uma capital que, ao longo de sua história, desenvolveu uma intensa vida cultural. Pelo menos desde a década de 1920, escolas de balé já se fazem presentes na cidade, onde há cursos de graduação em dança desde $1998 .{ }^{4}$

O recorte que trazemos neste texto surge a partir de um estudo etnográfico. Segundo Geertz (1989, p. 63), o trabalho de articular aquilo que se vivencia no local implica "[...] uma presença do Lá em um texto elaborado Aqui'. Durante o trabalho de campo, foram realizadas seis etapas. ${ }^{5}$ Neste artigo, focamos na última delas, uma observação participante em um clube do bairro onde se localizava uma escola de balé. Algumas crianças da escola participavam das aulas. Além dos diários de campo, foi realizada uma entrevista com a criança (Rodrigo), outra

\footnotetext{
3 Foucault (2002, p. 244) define o dispositivo da sexualidade como "Um conjunto decididamente heterogêneo que engloba discursos, instituições, organizações arquitetônicas, decisões regulamentares, leis, medidas administrativas, enunciados científicos, proposições filosóficas, morais, filantrópicas. Em suma, o dito e não dito são elementos do dispositivo. 0 dispositivo é uma rede que se pode estabelecer entre estes elementos".

4 Universidade Luterana do Brasil.

5 Etapas: 1: observações na escola em turmas da primeira à quarta série, levantamento das crianças e mapeamento no Google Maps, diários de campo; 2: realização e aplicação dos questionários, observações no bairro, fora do horário escolar, realização de entrevistas com crianças, utilização das fichas nas atividades extras na escola; 3: escolhas e observação de duas turmas; 4: grupos focais com crianças; 5 : 38 entrevistas com pais ou responsáveis das crianças e com alguns professores; 6: observação, no clube, de um menino que realizava balé. Entrevistas.
} 
com sua mãe, uma em conjunto com dois de seus professores (pois dividiam as mesmas aulas) e duas entrevistas individuais com as duas mães das colegas meninas que frequentavam 0 mesmo clube e a mesma escola. As entrevistas foram semiestruturadas por permitirem uma maior flexibilidade para tratar das ideias expressas, possibilitando que a pesquisa seja uma construção de leituras, reflexões e investimentos (ALBARELLO et al.,1997).

Das crianças entrevistadas nas primeiras etapas da pesquisa, Rodrigo era a que realizava mais atividades. Foram quatro modalidades: balé, natação, futebol e hip-hop. $\mathrm{Na}$ escola, ele não realizava atividades que o diferenciassem durante as brincadeiras do recreio. Assim, na sexta etapa, o objetivo foi aprofundar o olhar sobre alguma criança que praticava muitas atividades, algumas delas não tradicionalmente reconhecidas como adequadas para seu gênero. Observamos suas aulas no clube durante um mês, três vezes por semana, com uma duração aproximada de uma hora.

Rodrigo começou a fazer balé na creche que frequentava, pois fazia parte de umas das atividades oferecidas. Ao perguntarmos sobre como foi o início dessa prática, a mãe respondeu:

Ele gostava, ele se mexia, ele se sacudia para tudo que é lado, né? [...] Ele simplesmente chegou pra nós e perguntou: 'Eu posso dançar balé?', 'Pode'. Nem houve aquele olhar ou alguma coisa de... Nem passou, sinceramente, nem passa pela nossa cabeça, porque ele é uma criança ativa, ele gosta de dançar, ele gosta de ouvir música (MARIA, 2011, grifos nossos).

Como pode ser identificado na fala da mãe, os pais atribuem a prática do balé também ao gosto pelo movimento e pela música. "Aquele olhar" que destacamos no trecho aponta para os preconceitos que os pais percebem que estão presentes e relacionados com o balé, mas que não os fizeram desestimular Rodrigo a dançar.

As aulas aconteciam em uma escola de dança que funciona dentro de um clube ${ }^{6}$ tradicional da cidade, que iniciou suas atividades com o loteamento da região e começou com verbas doadas pelos próprios moradores. Além da coordenadora, a escola tem nove professores(as), que oferecem as seguintes modalidades e turmas: baby class, balé clássico, jazz e hip-hop. Rodrigo conciliava as atividades e, aparentemente, gostava muito de praticálas.

\section{DANÇA E MASCULINIDADE}

A história de Rodrigo nos chama a atenção especialmente por ele ser um menino que dança balé, o que nos ajuda a tensionar uma prática que ainda hoje é considerada hegemonicamente feminina. Nesta seção, vamos aprofundar esse tema, resgatando pontos significativos da história do balé no que toca à participação de homens. Também utilizaremos essa contextualização para discutir sobre a dança como local de performance de gêneros e, por fim, refletir sobre como Rodrigo e outros homens nos ajudam a pensar sobre a produção de masculinidades na dança.

Embora a origem do balé remeta a uma dança social no período do Renascimento, na Itália (século XV), ele ganha notoriedade pela influência da corte francesa. O Rei Luis XIV, conhecido como Rei Sol, funda a Academia Real de Ballet em 1661. Com isso, leva essa dança para os teatros com bailarinos profissionais, incluindo alguns atletas e ginastas

6 Não identificaremos o clube nem a escola para proteção da identidade da criança. 
(ASSIS, 2012). Nessa época, a dança era executada somente por homens e tinha como foco a valorização do belo e da realeza. As mulheres foram incluídas na Academia apenas em 1681, com Mademoiselle Lafontaine, porém ainda de forma secundária e com movimentos limitados (ARAÚJO, 2017).

Na primeira metade do século XVIII, Marie Camargo, uma bailarina belga, fez várias modificações nos movimentos e no vestuário, encurtando a saia, tirando o salto, elevando mais as pernas e fazendo saltos antes reservados apenas aos homens (HANNA, 1999). Porém, a supremacia masculina no balé só é questionada a partir do século XIX, quando Maria Taglioni subiu à ponta dos pés e trouxe a leveza à representação feminina no balé. Após isso, o bailarino passa a desempenhar o papel secundário de sustentação da bailarina, perdendo espaço nos palcos e valorizando mais os espaços esportivos (MELO; LACERDA, 2009).

Com as novas demandas da sociedade industrial europeia, somadas à desvalorização dos papéis masculinos, a presença dos homens no balé se torna cada vez menor. De acordo com Andreoli (2011, p.162), "O Balé, com sua estética originária de um modo de se movimentar da nobreza do século XVIII e, portanto, do modelo de masculinidade anterior, passa a ser um dos símbolos que essa nova representação procurou negar".

Alguns destaques podem ser citados, como Vatslav Fomitch Nijinski, bailarino russo que, no início do século XX, impressionou com seus saltos. Segundo Assis (2012, p.61), "[...] como dançarino, Nijinsky foi tão dinâmico e habilidoso que foi saudado como um gênio do sexo masculino, sendo uma figura chave na reintrodução do balé masculino do século XX [...]". Para essa autora, uma forma de manter os homens no palco era provar que o balé era difícil e que poderia conter as características de "macho". Os balés russos ajudaram na produção dessa diferenciação de papéis masculinos e femininos. Vale lembrar que esses papéis nos bastidores continuaram sendo dos homens, como diretores, produtores e empresários.

Novas disputas voltam a acontecer com a dança moderna. Especialmente pela criação de papéis femininos fortes, como as de Martha Graham e Ruth St. Denis. ${ }^{7}$ Também é preciso considerar novas tentativas de participação mais efetivas de homens, como Ted Shawn. ${ }^{8}$

Porém, a percepção do balé como prática feminina ainda persiste, conforme podemos notar na fala de Rodrigo (2011). Quando perguntamos como ele entende a participação dos meninos no balé, ele destacou:

Rodrigo: Não sei. Não sei se é vergonha de fazer ou se é por não saber a diferença, tipo, aí eu não vou fazer porque balé é coisa de guria.

lleana: Você já ouviu aquilo...?

Rodrigo: Já, meu primo uma vez falou pra mim: 'Não, eu não quero ir lá, é coisa de guria”, depois eu perguntei: 'Tá, e tu acha que eu sou guria?'. Daí ele começou a pensar e não me falou mais nada.

Com essa rápida síntese histórica e apontamentos, concordamos com Santos (2009, p. 35) quando afirma:

Mesmo antes da normatização técnica da dança clássica, aprender a dançar balé significava dar-se a ver de uma determinada forma, não somente por meio do domínio do código de movimentos específicos, mas também pelos modos e as maneiras de civilidade e boa educação, tal qual o era na sua origem.

7 Dançarinas/coreógrafas norte-americanas.

8 Dançarino/coreógrafo norte-americano. 
Chamamos a atenção aqui para os modos e maneiras de produção de marcas de gênero. "Em outras palavras, dançar é performance marcada pelo gênero, com inevitáveis conexões com a sexualidade. Ninguém dança sem carregar consigo impressões ligadas a gênero e sexualidade" (SEFFNER; SANTOS, 2012, p. 3). Exemplo dessa preocupação é percebido quando perguntamos a Rodrigo (2011) sobre acontecimentos na escola e ele destacou um evento:

Rodrigo: Sim. Eu estava jogando futebol, daí veio uma colega minha do balé, que fazia balé comigo, veio conversar alguma coisa e estava com uma foto que a gente tirou numa apresentação. Daí uma colega minha chegou correndo no pátio: 'Ah, o Rodrigo faz balé, o Rodrigo faz balé'. Começaram a mexer comigo, a brincar assim, seguido.

lleana: E falavam o quê?

Rodrigo: Ah ficavam falando, o Rodrigo é bicha, é bicha, bicha. Eles diziam: 'As gurias ficam te agarrando e tu não fica com elas, então tu é bicha, tu é bicha'. Essas coisas assim.

Ileana: $\mathrm{E}$ o que aconteceu?

Rodrigo: Eu ficava na minha, não falava nada, eu não dava bola.

Como podemos observar, o corpo e a prática do balé parecem determinar a sexualidade. A família de Rodrigo (2011), embora reconheça a presença dessas ideias, não concorda com essa relação direta entre atividade e sexualidade, como vemos abaixo:

Maria: Eu acho assim, se tiver que ser, ser algo diferente... Eu digo assim, se ele vier optar pela sexualidade dele, uma outra opção, ter preferência, a gente vai receber numa boa.

lleana: Mas, em princípio, para vocês, a atividade em si, a dança em si não tem nada a ver com a opção sexual?

Maria: Não! Não tem nada que ver com a sexualidade dele, entendeu? Porque ele é uma criança ativa, ele gosta de dançar, ele gosta de ouvir música.

Assim, as situações relatadas refletem algumas das dificuldades para a inclusão do corpo masculino nas práticas corporais, especialmente quando se trata de algumas modalidades de dança, como o balé (GONÇALVES, 2014). Ideias preconceituosas associadas à orientação sexual promovem a discriminação, estigmatização e até a violência contra 0 homem praticante.

Isso também em relação ao gênero. Para Jakubowska e Byczkowska-Owczarek (2018), ainda persiste a divisão entre atividades "para meninos" e "para meninas", refletindo padrões socioculturais e corporais ligados a uma feminilidade ou masculinidade "apropriada". Dessa forma, o balé, aparentemente delicado e belo, encaixa-se na expectativa de uma atividade feminina, refletindo a grande maioria de praticantes meninas e mulheres. No Brasil, vários estudos já apontaram essa predominância e a relação com as características e a história da prática do balé (ANDREOLI, 2011; MELO; LACERDA, 2009; SARAIVA, 2003).

Dentro desse contexto, é preciso considerar que, no balé, assim como na maioria das danças, nas aulas, no cotidiano ou nas apresentações, existem formas de atuar também consideradas mais adequadas para meninos ou para meninas. Exemplos claros disso são as sapatilhas de ponta, que, no geral, competem às meninas, e as sustentações de outros corpos, função determinada para os meninos, mas a própria gestualidade é específica e diferente para meninos e meninas (SANTOS, 2009). Elas, delicadas e frágeis; eles, altivos e fortes. 
Com isso em mente e tentando pensar no caso do Rodrigo, vemos que a presença dos homens no balé nunca deixou de existir, embora tenha passado por momentos diferentes em relação à sua forma estética e valorização. Aqui adentramos outro aspecto que gostaríamos de destacar referente aos sujeitos envolvidos nesta pesquisa: o que era alvo de atenção não era se o menino dançava balé, mas como ele dançava. Ou seja, a questão em relação ao gênero ou à sexualidade do menino dançante não era alvo de preocupação por nenhum dos integrantes. 0 que importava entre eles era 0 aspecto técnico da dança. A mãe cobrava da professora:

O Rodrigo vai ser aquele que vai sempre segurar a menina? Não tem a dança do menino? Do rapaz, né? Aquela coisa que o Rodrigo era sempre quem levantava as meninas, segurava a menina, mas isso tudo na minha, entendeu? Uma coisa minha, eu que questionava, ele não questionava isso (MARIA, 2011).

Percebemos que a produção histórica do balé se reflete ainda nos dias de hoje, tanto pela secundarização dos papéis masculinos quanto pela divisão das performances de meninos e meninas. Em relação a Rodrigo, professora e mãe discordavam na questão da técnica. A professora, que era nova na escola, percebia que, embora Rodrigo dançasse desde criança, ele não tinha um desenvolvimento técnico adequado, e isso podia ser atribuído às possíveis limitações de uma escola de balé de bairro. A professora comenta esse fato não somente se reportando ao caso de Rodrigo, mas também às outras alunas que não estavam prontas para colocar sapatilhas de ponta, e as mães delas cobraram, visto que entendiam que "já estava na hora". Além disso, a professora compreendia que ele tinha muitas atividades e isso dificultava uma maior dedicação, disciplina e compromisso necessários para desenvolver o balé em um nível aceitável, como pode ser observado em sua fala a seguir:

\begin{abstract}
A família dele é espetacular. Mãe traz, pai vai, assiste ao espetáculo, sabe? Pai traz, eles incentivam porque ele joga futebol e dança balé clássico. As pessoas têm que entender que não é porque tu dança balé clássico com a roupinha coladinha que tu vai mudar tua opção sexual. Tem muitos homossexuais que não dançam balé, assim como têm muitos bailarinos clássicos que não são homossexuais, só que a sociedade ainda tem essa mentalidade, e não é isso que acontece com 0 Rodrigo. A família apoia, e eu só acho que falta esforço dele. Assim como elas [as colegas], ele não teve base e ele poderia já estar muito melhor, porque ele é homem e ele começou cedo [...]. Rodrigo, que começou cedinho, não teve a base, sabe? Agora ele já tá numa idade que tá difícil de trabalhar, e ele falta muito. Ele vem às vezes uma vez por semana [...] só que assim, pra ele melhorar, ele teria que fazer, no mínimo, três aulas por semana, e querer [...]. Eu acho uma pena, eu acho que ele teria condições no balé, só que se ele não se esforça. Se ele continuar sem se esforçar do jeito que ele tá, ele não vai conseguir crescer (PROFESSORA, 2011, p. 16).
\end{abstract}

A preocupação técnica no cotidiano do balé é comum para todos(as) os(as) praticantes. Talvez essa necessidade de dedicação mais intensa e exclusiva também seja um fator que afaste meninos dessa prática, haja vista que há a expectativa de que eles realizem mais atividades ativas do que as meninas. Porém, além disso, a literatura consultada aponta uma preocupação ainda maior entre a técnica e a produção da masculinidade.

Os homens que fizeram uma vida decente como dançarinos nos séculos XVIII e XIX foram aqueles que usaram os pés como ferramentas e não agitaram os braços e fizeram atitudes afetadas. 0 popular coreógrafo performer John Durang começou a fazer seu nome com seu solo de trompete, enquanto o menestrel afroamericano William Henry Lane emocionou Londres com sua agilidade e rapidez. 
Não está claro exatamente quando a acusação de efeminação começou a ser relacionada aos dançarinos do sexo masculino, ou quando um garoto que estuda balé pode ser considerado um maricas (JOWITT, 2010, p. 228-229).

Para a autora, Ted Shawn desenvolveu duas estratégias para ter uma carreira de sucesso na dança: "Uma era assumir uma série de papéis exóticos estereotipados que combinavam com os de Ruth St. Denis, codificando a virilidade e o poder de maneiras que detonam sua espiritualidade sensual" (JOWITT, 2010, p. 230). "A outra estratégia de Shawn (JOWITT, 2010, p.231) era empurrar a conexão entre dança e esportes, dançarinos e atletas". Essa diferenciação também é ressaltada pelo professor de Rodrigo (2011):

Eu tive aula com uma mulher, e quando eu tive aula com um professor homem foi algo totalmente diferente, porque tu começa... Eu dançava, fazia umas coisas, mas fazia como menina, e não é o que uma companhia, ou uma competição querem. Eles não querem te ver ficar dançando que nem uma menina no palco; eles querem ver um homem dançando.

Assim, concordamos com Kimmel (1998), que observa que é necessário entender que as masculinidades são plurais e socialmente construídas. Além disso, sua produção se dá simultaneamente em dois campos de relação de poder: entre homens e mulheres e entre homens e outros homens. $\mathrm{O}$ autor, ao estudar a masculidade nos Estados Unidos, aponta que, no final do século XVIII, coexistiam dois modelos de masculinidade:

O primeiro destes modelos é o que eu chamo de Patriarca Gentil, aquele que derivou sua identidade da posse da terra. Ao supervisionar suas propriedades rurais, ele era refinado, cordial, elegante e dado a uma certa sensualidade. Ele era um pai dotado e devotado, que passava muito do seu tempo com a sua família e cuidando seus domínios (KIMMEL, 1998, p. 109).

O segundo modelo desse período seria o Artesão Heroico, que demonstrava força e virtude republicana, trabalhava duro e passava aos seus filhos a sua arte. Porém, esses modelos começam a ser menos representativos a partir do século XIX, quando, segundo o autor, emerge o Self-Made Man. Nesse modelo, "A sua masculinidade deveria ser demonstrada e provada no mercado. Ele era um empresário urbano, um homem de negócios [...]. Tal definição de masculinidade era inerentemente instável, exigindo comprovação constante, incluía sempre o risco de falhar" (KIMMEL, 1998, p. 111).

Considerando essa definição, especialmente sua relação com o mercado de trabalho, Seffner e Santos (2012) destacam que essa masculinidade afasta os homens da dança, visto que ela não se apresenta como uma atividade rentável, que possibilite o sustento de uma família. Segundo Araújo (2017, p. 42), "Outros fatos históricos que contribuíram para tal afastamento foram as revoluções Francesa e Industrial, pois, a partir delas, o papel cultural do homem deve estar relacionado à força de trabalho, produção e à defesa da família, afastando-o do universo da arte".

Kimmel (1998) ainda aponta três padrões básicos para provar e demonstrar a masculinidade Self-Made Man: autocontrole, fuga para as florestas, exército, mar (homem versus natureza) e, principalmente, a desvalorização de outras formas de masculinidade. ${ }^{9}$ Sobre este último padrão, o autor comenta:

9 No contexto brasileiro ao que nos parece a questão da virilidade, como potência sexual, é bem mais valorizada do que o "homem versus natureza". Isso pode ser percebido em trabalhos como o de Giuseppe e Romero (2007) e também no episódio em que Rodrigo aponta que um dos questionamentos sobre sua sexualidade foi feito por colegas, já que ele não "pegava as meninas". Kimmel também cita essa questão ao falar do "sexualmente voraz". 
Em primeiro lugar, o Self-Made Mantinha que desmontar duas definições anteriores de masculinidade, o Patriarca Gentil e o Artesão Heróico. O Patriarca Gentil foi redefinido como um pavão europeu afetado, uma 'bichinha' do século XIX. [...] E o Artesão Heróico tornou-se, no decorrer do século XIX, o trabalhador comum, a mão-de-obra, uma peça da máquina [...]. Ou bem era-se muito másculo - isto é, sexualmente voraz, bestialmente violento, incapaz de controlar desejos carnais -, ou então não se era 'masculino o suficiente', ou seja, indefeso, dependente, passivo, feminilizado (KIMMEL, 1998, p. 111).

Percebemos que a busca pela beleza, a expressão de sentimentos e a não rentabilidade presentes no balé acabam por não contribuir para a formação dessa masculinidade hegemônica. Assim, são aceitas formas de dança que aparentem mais força, mais dominância, mais competição. Relacionamos, então, o balé com uma masculinidade subalterna, como aponta Kimmel. Ou seja, ela se produz em diálogo com outras masculinidades, mas não é tão valorizada e rompe com questões da masculinidade heteronormativa. Seffner e Santos (2012), ao falarem sobre os meninos que dançam hip-hop, apontam que eles enfrentam várias questões e negociações, por vezes polarizadas, especialmente no que se refere à construção de uma masculinidade "aceitável". Segundo esses autores, "Além do hip-hop, pais e professores por vezes estimulam o menino a dançar música típica gaúcha, ou até dança de salão. Mas o balé, o jazz, o sapateado e outros ritmos semelhantes são vivamente condenados" (2012, p. 3). A história de um dos professores de Rodrigo confirma essa citação:

Professor: Eu dancei invernada antes no CTG um tempão e fiz sapateado americano, aí, logo depois, aos 16 anos, eu fiz umas aulas de hip-hop. Gostei. Daí parei e quando fiz 18 anos comecei a dançar de novo.

lleana: Mas aí foi o balé?

Professor: Daí foi para o balé. Voltei pro hip-hop. Sapateado eu continuei fazendo, que eu já fazia antes, porque minha mãe era professora de sapateado.

Novamente retornamos ao diálogo e negociação com masculinidades mais hegemônicas, o que também é percebido quando algumas formas de dança buscam uma hipermasculinização (demonstração de força, habilidades atléticas, raiva etc.). Isso pode ser, inclusive, uma estratégia para ampliar a participação de meninos, a exemplo do que acontece no Projeto Boys Dancing, que surgiu no Reino Unido:

O desafio para os facilitadores Boys Dancing tem sido o de abraçar o normativo como legítimo - o jovem macho como forte e poderoso - enquanto abre um espectro mais amplo de estados emocionais e respostas através de uma variedade de formas coreográficas e gatilhos imaginativos (HOLDSWORTH, 2013, p. 173).

Ainda em relação a essa negociação, trazemos um último ponto de tensão, que são as vivências no espaço escolar. Esse ponto nos chamou a atenção porque, para a mãe, não há uma problemática entre sexualidade e o balé, porém ela relata: "Então, esse negócio 'ah, sexualidade, de repente interfere...'[...]. A não ser aquilo que eu e falei, né? Na escola, que ele prefere não dizer. Ele não sabe como é que os colegas vão interpretar, não comenta" (MARIA, 2011).

Qual será o motivo desse silenciamento na escola? A dança na escola é uma relação muitas vezes não fluida. Em publicações anteriores [retirado para avaliação cega], foi apresentado como os meninos, ao dançarem, faziam de conta que não dançavam ou realizavam os movimentos exageradamente.

Ao relatar uma intervenção de dança na escola, Kleinubing, Saraiva e Francischi (2013, p.76) afirmam que a reação dos alunos foi se transformando: "[...] a empolgação inicial 
desaparecia na medida em que o movimento começava a ser detalhado e racionalizado, para ser 'melhor' realizado", repetindo, assim, o que percebemos no contexto geral da dança: não é simplesmente o dançar, mas o "como" se dança.

Segundo as autoras, temos aqui uma pequena diferenciação nos movimentos. A dança

[...] oferece um cenário no qual a sensualidade e a sensibilidade (aspectos totalmente aceitáveis para as meninas) tomam corpo e, então, os movimentos, (des)encontros corporais podem ser lidos de diferentes formas inclusive de forma maliciosa e com carácter depreciativo com relação às meninas, aspecto que pode se acentuar com relação aos meninos (KLEINUBING; SARAIVA; FRANCISCHI, 2013, p.79).

Como podemos observar, a possibilidade do conteúdo dança na escola pode ter múltiplos significados. Desse modo, em sua experiência, as autoras observaram tanto a promoção dos estereótipos quanto o tensionamento e "[...] a emergência de outras formas de pensar o movimento na dança, implicando nas escolhas dos jovens sobre suas práticas corporais e nos seus modos de viver" (KLEINUBING; SARAIVA; FRANCISCHI, 2013, p.80). Rodrigo não comenta, mas também não esconde como, na situação em que o chamaram de bicha, ele "não dá bola". Mesmo assim ele ainda passa por situações em que precisa fazer esforço para não se importar. Como a escola é um espaço de socialização importante para as crianças, esses enfrentamentos também nos ajudam a entender que, embora a participação de meninos no balé possa ser menos problemática com discussões sobre essas questões, nos dias atuais, ainda há um longo caminho a percorrer para que meninos e meninas tenham mais liberdades em suas atividades.

\section{POR QUE O BALÉ É COISA DE MENINO?}

Chegando ao final deste texto, percebemos que a dança, especialmente o balé, ainda enfrenta desafios para a entrada e permanência na pratica do balé por meninos e homens, vinculados a questões de gênero e sexualidade, porém o caso de Rodrigo nos mostra que é possível que um menino frequente aulas de balé e não seja "expulso" socialmente delas.

Sua presença se efetiva tanto pelas condições pessoais (ele gosta e não se importa com questionamentos e comentários preconceituosos), educacionais e culturais da família (que o apoia e não coloca problemas), quanto pelas negociações feitas entre o menino, a escola, os professores, a família e a sociedade (o papel masculino no balé). Questões fundamentais, haja vista a centralidade da família e da escola na infância.

Também se faz necessário notar que, a partir dos processos históricos que tensionam e discutem práticas "adequadas" para meninos e meninas, houve uma abertura maior tanto para a participação de meninos em práticas como o balé, quanto de meninas em atividades como o futebol. Para além das discussões educacionais e acadêmicas, Holdsworth (2013), em seu estudo no Reino Unido, cita a influência de filmes e programas televisivos de dança que estão cada vez mais presentes, o que podemos perceber também no Brasil.

Assim, vemos que, culturalmente, parece cada vez mais aceitável que as práticas sejam abertas à participação de meninos e meninas, e não negadas a eles(as). Acreditamos que casos como o de Rodrigo se tornaram possíveis porque a visão de masculinidades tem se tornado plural. Isso não significa dizer que essa questão está resolvida, mas esperamos que 
este caso/texto abra a possibilidade de mais estudos e ações que fortaleçam e deem mais liberdade às práticas de dança.

\section{REFERÊNCIAS}

ALBARELLO, Luc et al. Práticas e métodos de investigação em ciências sociais. Lisboa: Gradiva, 1997.

ANDREOLI, Giuliano. Representações de masculinidade na dança contemporânea. Movimento, v. 17, n. 1, p. 159-175, 2011. Disponível em: https://seer.ufrgs.br/Movimento/article/view/16175. Acesso em: 5 out. 2018.

ARAÚJO, Lucas. 0 homem na dança: entre a análise histórica e a análise dos princípios corporais do ballet clássico. 2017. 50 f. Trabalho de Conclusão de Curso (TCC) - Universidade Estadual de São Paulo, Rio Claro, 2017.

ASSIS, Marília. Acerca do feminino e do masculino na dança. 2012. 130 f. Dissertação (Mestrado em Educação Física) - Programa de Pós-Graduação em Educação Física, Universidade Federal de Santa Catarina, Florianópolis, 2012. Disponível em: https://repositorio. ufsc.br/handle/123456789/99220. Acesso em: 15 dez. 2018.

FOUCAULT, Michel. Vigiar e punir. Petrópolis: Vozes, 2002.

GEERTZ, Clifford. Estar lá, escrever aqui. Diálogo, v. 22, n. 3, p. 58-63, 1989.

GIUSEPPE, Erik; ROMERO, Elaine. Para ser macho não pode negar fogo, tem que ser viril. Revista Entreideias, v. 9, n. 8, 2007. Disponível em: https://portalseer.ufba.br/index.php/ entreideias/article/view/2821. Acesso em: 25 nov. 2018.

GONÇALVES, Adriane. Sexualidade, masculinidades e dança. In: FREITAS, Eliane; MARTINEZ, Fabiana; MENDES, Lilian (org.). Gênero, sexualidade e corpo. Goiânia: Gráfica UFG, 2014. p.101-114.

HANNA, Judith. Dança, sexo e gênero. Rio de Janeiro: Rocco, 1999.

HOLDSWORTH, Nadine. Boys don't do dance, do they? Research in Drama Education: The Journal of Applied Theatre and Performance, v. 18, n. 2, p. 168-178, 2013.

JAKUBOWSKA, Honorata; BYCZKOWSKA-OWCZAREK, Dominika. Girls in football, boys in dance. Qualitative Sociology Review, v. 14, n. 2, p. 12-28, 2018.

JOWITT, Deborah. Dancing Masculinity. Southwest Review, v. 95, n. 1/2, p. 228-242, 2010.

KIMMEL, Michael. A produção simultânea de masculinidades hegemônicas e subalternas. Horizontes Antropológicos, v. 4, n. 9, p. 103-117, 1998. Disponível em: http:// www.scielo.br/pdf/ha/v4n9/0104-7183-ha-4-9-0103.pdf. Acesso em: 25 nov. 2018.

KLEINUBING, Neusa; SARAIVA, Maria; FRANCISCHI, Vanessa. A dança no ensino médio. Educação Física/UEM, v. 24, n.1, p.71-82, 2013. Disponível em: http://ojs.uem.br/ojs/index.php/ RevEducFis/article/view/15459/11486. Acesso em: 20 abr. 2017. 
LOURO, Guacira (org.). 0 corpo educado: pedagogias da sexualidade. Belo Horizonte: Autêntica, 1999.

MELO, Victor; LACERDA, Claudio. Masculinidade, dança e esporte. Revista Brasileira de Ciências do Esporte, v. 30, n. 3, p. 45-62, maio 2009. Disponível em: http://rbce.cbce.org.br/ index.php/RBCE/article/download/221/382. Acesso em: 9 jan. 2019.

MEYER, Dagmar. Gênero e educação: teoria e política. In: LOURO, Guacira; FELIPE, Jane; GOELLNER, Silvana (org.). Corpo, gênero e sexualidade. Petrópolis: Vozes, 2003. p. 9-27.

NICHOLSON, Linda. Interpretando o gênero. Revista Estudos Feministas, v. 8, n. 2, p. 9-42, 2000. Disponível em: https://periodicos.ufsc.br/index.php/ref/article/view/11917. Acesso em: 11 jun. 2018.

SANTOS, Tatiana. Entre pedaços de algodão e bailarinas de porcelana. 2009. 95 f. Dissertação (Mestrado em Educação) - Programa de Pós-Graduação em Educação, Universidade Federal do Rio Grande do Sul, Porto Alegre, 2009. Disponível em: https://lume. ufrgs.br/handle/10183/21386. Acesso em: 23 out. 2018.

SARAIVA, Maria. Dança e gênero na Escola. 2003. 234 f. Tese (Doutorado em Motricidade Humana) - Faculdade de Motricidade Humana, Universidade Técnica de Lisboa, Lisboa, 2003.

SCOTT, Joan. Gênero: uma categoria útil de análise histórica. Educação \& Realidade, v. 20, n. 2, p. 71-79, jul./dez. 1995. Disponível em: https://edisciplinas.usp.br/pluginfile.php/185058/mod resource/content/2/G\%C3\%AAnero-Joan\%20Scott.pdf. Acesso em: 23 out. 2018.

SEFFNER, Fernando; SANTOS, Éderson. Ser homem, ser bom aluno, ser dançarino: tudo isso se aprende na escola. Revista Artifícios, v. 2, n. 4, 2012. Disponível em: https://www. researchgate.net/profile/fernando seffner2/publication/271272621 ser homem ser bom aluno ser dancarino tudo isso se aprende na escola/links/54c40d7e0cf256ed5a932f7b/ser-homem-ser-bomaluno-ser-dancarino-tudo-isso-se-aprende-na-escola.pdf. Acesso em: 25 jan. 2019.

WEEKS, Jeffrey. O corpo e a sexualidade. In: LOURO, Guacira. 0 corpo educado. Belo Horizonte: Autêntica Editora, 1999. p. 35-82. 